\title{
Ctenocephalides canis is the dominant flea species of dogs in the Republic of Korea
}

\author{
Kyu-Sung Ahn', Shin-Eui Huh', Sang-Woo Seol ${ }^{1}$, Ha-Jung Kim², Kuk-Hyun Suh ${ }^{2}$ and SungShik Shin ${ }^{1 *}$ (D)
}

\begin{abstract}
Background: The status of flea infestation in dogs is an important public health concern because of their cosmopolitan distribution worldwide and the flea-borne disease transmission. In the present study, we investigated the flea infestation among 116 outdoor dogs (57 females and 59 males) in 8 rural areas of Jeonnam Province, Republic of Korea.

Results: Thirty-three dogs (28.4\%) were infested with fleas, and all dogs were infested with Ctenocephalides canis. One dog from Hampyeong was co-infested with Ctenocephalides felis orientis, but no dogs were infested with Ctenocephalides felis felis. The reasons behind this almost exclusive distribution of flea species in dogs from Korea are currently unknown and will require further epidemiological and biological investigations. However, since all dogs investigated in the study were raised in an outdoor environment, the development of flea eggs, larvae and pupae in climatic conditions in Korea might have negatively affected the survival of other flea species. Due to the shoes-off culture and floor-heating system of Korean houses, indoor dogs are rarely infested with fleas in Korea.
\end{abstract}

Conclusion: To our knowledge, this is the first report on the distribution survey of flea species infesting dogs in Korea and the first report of C. orientis infesting a dog in Korea.

Keywords: Ctenocephalides canis, Ctenocephalides orientis, Dog fleas, Epidemiology, CVBD

\section{Background}

The dominant flea species infesting dogs in the USA, Mexico and western Europe is Ctenocephalides felis felis while in some countries in central and eastern Europe, as well as Ireland and Argentina the flea species is Ctenocephalides canis [1-6]. Ctenocephalides orientis (syn. Ctenocephalides felis orientis), on the other hand, is prevalent among dogs in Asian countries such as India, Malaysia and Thailand [7-10]. In cats, the major flea species is $C$. felis felis regardless of geographical region $[3,4,6,11]$. However, unlike in other countries, flea infestation among pet dogs and cats are rarely considered a serious issue among small animal practitioners in Korea and no clinical cases of flea infestation have been reported from client-owned pet dogs or cats. While dogs with allergic dermatitis due to house dust mites are reportedly high in Korea $(62 / 101,61.4 \%)$, positive rate for

\footnotetext{
* Correspondence: sungshik@jnu.ac.kr

'Department of Parasitology, College of Veterinary Medicine, Chonnam National University, 77 Yongbong-ro, Buk-ku, Gwangju 61186, Republic of Korea

Full list of author information is available at the end of the article
}

flea allergens was only $7.9 \%(8 / 101)$ [12]. Koreans customarily take off their shoes when they enter their homes and remain bare-footed indoors. For this reason houses possess an underfloor heating system that contributes to low-humidity conditions that do not favor survival and propagation of fleas [13, 14]. Carpets are rarely covered in the living room. Instead, floors are covered with laminate or hardwood which makes residential houses of Korea, as well as the dogs that live therein, relatively free of fleas.

Unlike flea-free indoor dogs, outdoor dogs do become infested with fleas in Korea. Previously, we investigated the prevalence of ectoparasite infestation among stray dogs in Gwangju City, Republic of Korea from November 2003 to August 2005 and found that $6.8 \%$ of 103 dogs in the study was infested with C. canis [15].

Flea infestation on dogs is important to control for the prevention of flea-borne diseases in dogs and flea-borne zoonosis to humans. Ctenocephalides fleas, especially $C$. felis, are known to transmit a variety of zoonotic pathogens such as Bartonella henselae, Bartonella clarridgeiae, Bartonella quintana, Rickettsia typhi and Rickettsia felis, 
which, in humans, can cause cat scratch disease, endocarditis and flea-borne spotted fever, respectively [16-22]. However, an epidemiological survey on flea species in dogs has not been carried out in Korea. In this study, we aim to determine the prevalence and species of flea infesting outdoor dogs in Jeonnam Province in Korea.

\section{Methods}

Between January 2016 and October 2017, 116 dogs from 8 regions of Jeonnam Province, Korea were examined (Fig. 1). Village households in the study area were randomly visited and if dogs were sighted in the yard, owners were offered a free-health check for their dogs. During this time dogs were inspected for flea infestation using flea comb and visual examination for flea dirt on the skin. Dogs were of random breed, sex and age. All dogs in the study were outdoor dogs that had been kept outdoors in dog kennels and were not raised or allowed to enter their owner's indoor residential areas.
Veterinarians performed an initial inspection of dogs for the presence of fleas on the skin. Dogs were combed over the entire body, but only up to three adult fleas were collected from each dog for identification to minimize the potential bias in the distribution pattern of different flea species due to variations in the flea numbers per dog.

The collected fleas were stored in 70\% ethanol and transferred to the Department of Parasitology, Chonnam National University College of Veterinary Medicine. Fleas were mounted on slide glasses in polyvinyl alcohol-lactic acid (PVA) mounting medium [23]. Fleas were sexed and identified to species using a compound microscope with the aid of keys and descriptions from literature $[7,24,25]$.

\section{Results}

Out of 116 dogs investigated in this study, 33 dogs (28.4\%) were infested with fleas (Table 1). The highest

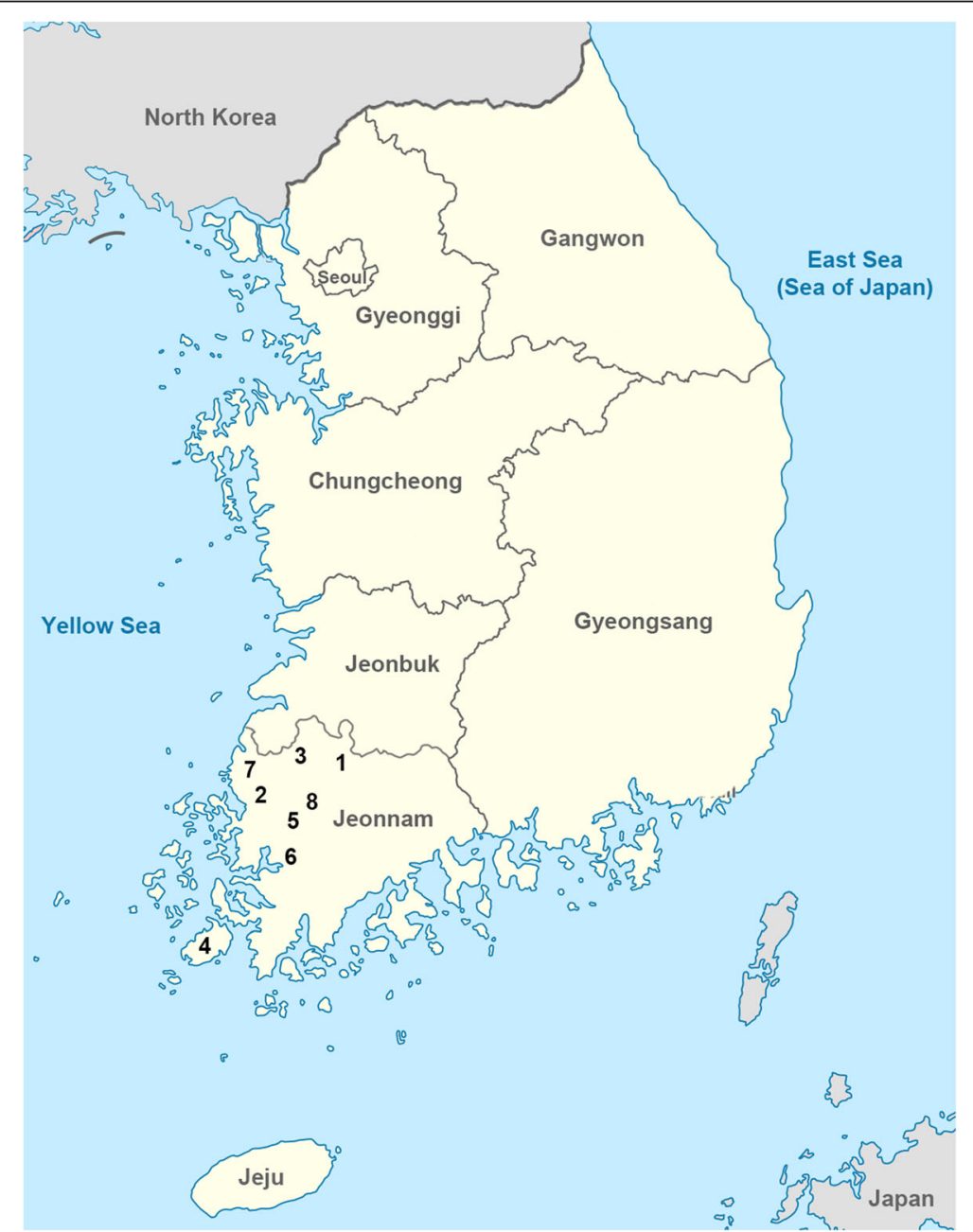

Fig. 1 Map of the study area in the southwestern Korean Peninsula. Flea infestation was investigated in dogs from 8 local areas: Damyang (1), Hampyeong (2), Jangseong (3) Jindo (4), Naju (5), Yeongam (6), Yeongwang (7) and SongJeong (8) 
Table 1 Infestation status of outdoor dogs with fleas in the southwestern regions of Korea

\begin{tabular}{|c|c|c|c|c|c|c|c|c|c|c|c|c|c|c|c|c|c|}
\hline \multirow[t]{3}{*}{ Location } & \multirow{2}{*}{\multicolumn{3}{|c|}{$\begin{array}{l}\text { No. of dogs } \\
\text { examined }\end{array}$}} & \multirow{2}{*}{\multicolumn{2}{|c|}{$\begin{array}{l}\text { No. of dogs } \\
\text { with fleas }\end{array}$}} & \multicolumn{12}{|c|}{ No. of fleas collected from dogs } \\
\hline & & & & & & \multicolumn{3}{|c|}{ C. canis } & \multicolumn{3}{|c|}{ C. orientis } & \multicolumn{3}{|c|}{ C. felis felis } & \multicolumn{3}{|c|}{ Total } \\
\hline & $\mathrm{F}$ & M & Total & Number & Percent & $\bar{M}$ & $\mathrm{~F}$ & $\overline{\text { Total }}$ & $\bar{M}$ & $\mathrm{~F}$ & Total & $\bar{M}$ & $\mathrm{~F}$ & Total & $\bar{M}$ & $\mathrm{~F}$ & Total \\
\hline Damyang & 3 & 4 & 7 & 1 & 14.3 & 1 & 2 & 3 & 0 & 0 & 0 & 0 & 0 & 0 & 1 & 2 & 3 \\
\hline Hampyeong & 15 & 22 & 37 & 15 & 40.5 & 5 & 31 & 36 & 0 & 1 & 1 & 0 & 0 & 0 & 5 & 32 & 37 \\
\hline Jangseong & 11 & 6 & 17 & 3 & 17.6 & 1 & 7 & 8 & 0 & 0 & 0 & 0 & 0 & 0 & 1 & 7 & 8 \\
\hline Jindo & 8 & 5 & 13 & 5 & 38.5 & 9 & 2 & 11 & 0 & 0 & 0 & 0 & 0 & 0 & 9 & 2 & 11 \\
\hline Naju & 5 & 3 & 8 & 1 & 12.5 & 0 & 1 & 1 & 0 & 0 & 0 & 0 & 0 & 0 & 0 & 1 & 1 \\
\hline Yeongam & 5 & 10 & 15 & 4 & 26.7 & 2 & 9 & 11 & 0 & 0 & 0 & 0 & 0 & 0 & 2 & 9 & 11 \\
\hline Yeongwang & 5 & 4 & 9 & 1 & 11.1 & 0 & 2 & 2 & 0 & 0 & 0 & 0 & 0 & 0 & 0 & 2 & 2 \\
\hline SongJeong & 5 & 5 & 10 & 3 & 30.0 & 3 & 0 & 3 & 0 & 0 & 0 & 0 & 0 & 0 & 3 & 0 & 3 \\
\hline Total & 57 & 59 & 116 & 33 & 28.4 & 21 & 54 & 75 & 0 & 1 & 1 & 0 & 0 & 0 & 21 & 55 & 76 \\
\hline
\end{tabular}

Abbreviations: $F$ female, $M$ male

number of flea-infested dogs was recorded in Hampyeong $(15 / 37,40.5 \%)$. At least one dog from each town of Chonnam Province was infested with fleas. A total of 76 adult fleas, 21 males and 55 females, was collected.

The majority of flea specimens was identified as Ctenocephalides canis based on the morphology, which was characterized by a short, sharply vertical frons and a short, club-shaped dorsal incrassation (Fig. 2a). The posterior margin of the hind tibia had two notches bearing stout setae between the post-median and apical setae (Fig. 2b). One dog from Hampyeong was co-infested with Ctenocephalides orientis, as characterized by a short, rounded frons and a short dorsal incrassation
(Fig. 2c). The dorso-posterior margin of the hind tibia of this species had only one notch bearing a stout seta between the post-median and apical setae (Fig. 2d).

\section{Discussion}

This study clearly shows that a considerably high number of outdoor dogs in Korea is exposed to flea infestation, and almost all flea species from dogs are C. canis. The cat flea, C. felis felis, is the predominant species found in both cats and dogs worldwide including the USA and Europe $[1,2,11,26]$. On the other hand, $C$. canis was the most common flea species on dogs from Greece, Ireland and Argentina [3-5]. Since a sample of

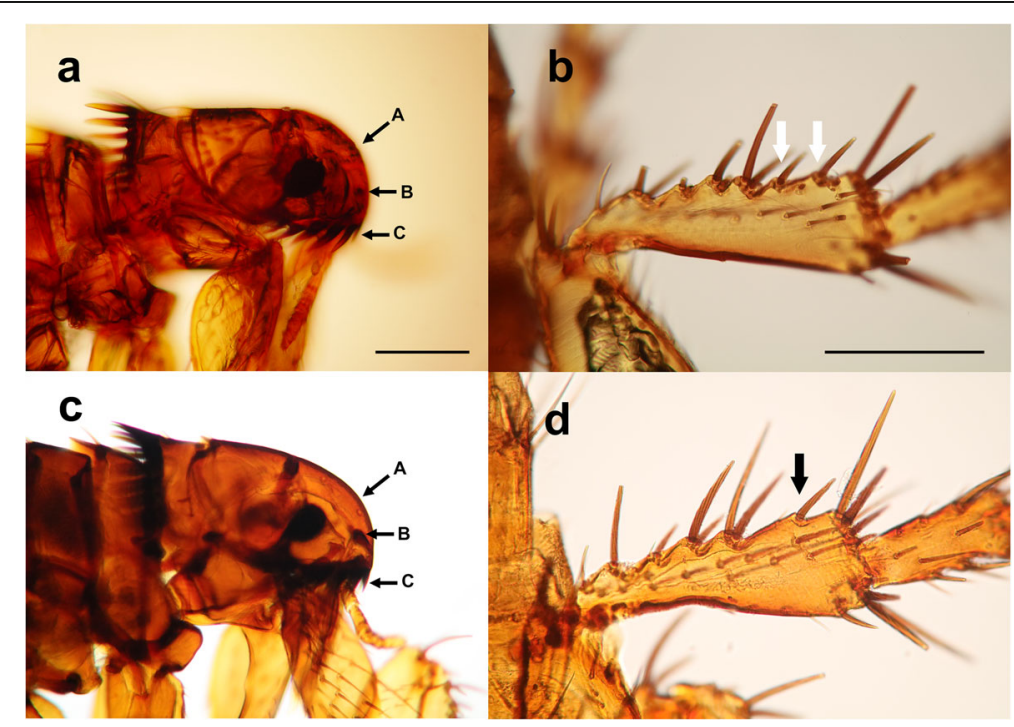

Fig. 2 Characteristic features of Ctenocephalides canis and Ctenocephalides orientis collected from dogs in Korea. a C. canis with a bluntly rounded frons or head (A) and a short stout dorsal incrassation (B). The first spine (C) of the genal ctenidia was close to half the length of the second spine. $\mathbf{b}$ The dorso-posterior margin of the hind tibia bore two notches with stout stetae (white arrows) between the post median and apical setae. c C. orientis was characterized by a round frons (A) and a short, club-shaped dorsal incrassation (B) similar to C. canis. The first spine (C) of the genal ctenidia was close to the length of the second spine (not in focus). $\mathbf{d}$ The dorso-posterior margin of the hind tibia bore one notch with stout stetae (black arrow) between the post median and apical setae 
116 dogs is not enough to draw conclusions about the exclusive distribution of $C$. canis in Korea and since an exclusive distribution of one species of fleas in a region is rather rare, results of this study call for further epidemiological research before making conclusions on the distribution of flea species in dogs from Korea.

The distribution pattern of C. felis felis and C. canis worldwide may depend more on the environmental than on-host factors. Most of the flea life-cycle, i.e. eggs, larvae and pupae undergo their developmental cycle off the host on the ground, so the temperature and humidity on the ground and in the dirt may significantly affect the survival of juvenile fleas.

Several previous reports support this assumption in that while C. felis felis was generally common among urban and indoor type dogs or cats [5, 27]; studies from Spain, Hungary and Germany indicated that C. canis were more common among rural and outdoor animals $[1,28,29]$. Also, wild animals such as red foxes were infested with C. canis [30]. The dog flea favors colder climates than the cat flea; thus, this species is more abundant in rural habitats and is largely confined to outdoor dogs [31-33]. According to the accumulative weather data recorded by the national meteorological service of the Republic of Korea (Korea Meteorological Administration, http://www.kma.go.kr/), the annual lowest and highest temperatures of the study area for 30 years between 1988 and 2017 were $-9.6 \pm 1.8{ }^{\circ} \mathrm{C}$ and $35.3 \pm 1.4{ }^{\circ} \mathrm{C}$, respectively (average $14.1 \pm 0.5{ }^{\circ} \mathrm{C}$ ). During the winter season, the average temperature for the same period in the study area was $2.4 \pm 0.9{ }^{\circ} \mathrm{C}$ (lowest $-9.6{ }^{\circ} \mathrm{C}$, highest $17.7{ }^{\circ} \mathrm{C}$ ). The cold winter season of Korea may therefore be too harsh for the juvenile developmental stages of many flea species that are adopted to warm climate, and only those species that can withstand such harsh outdoor weather condition may better be able to survive.

Only one dog in the survey hosted C. orientis. Formerly known as $C$. felis orientis, the species appears to be phylogenetically closer to $C$. canis than $C$. felis because $C$. canis formed a sister clade to C. orientis, not C. felis felis. [24, 34, 35]. Ctenocephalides orientis has been reported to be found in Asian countries such as India, Malaysia and Thailand $[7-9,24]$, and this study is the first report of $C$. orientis found in dogs from Korea. Other subspecies of $C$. felis are geographically restricted, such as C. felis damarensis in south-western Africa and C. felis strongylus in the Ethiopian zoogeographical region [7].

\section{Conclusions}

We investigated the flea infestation among outdoor dogs raised in eight rural areas of Jeonnam Province, Republic of Korea and showed that $28.4 \%$ of dogs were infested with C. canis, the dog flea and one dog co-infested with
C. orientis. No dogs were infested with C. felis felis. To our knowledge, this is the first report on the distribution survey of flea species infesting dogs in Korea and the first report of $C$. orientis infesting a dog in Korea.

\section{Acknowledgements}

Publication of this paper has been sponsored by Bayer Animal Health in the framework of the 13th CVBD World Forum Symposium.

\section{Funding}

This study was supported by the Ministry of Agriculture, Food and Rural Affairs, Republic of Korea (Grant No. 315016-3-C00).

\section{Availability of data and materials}

The datasets used in the present study are available from the corresponding author upon reasonable request.

Authors' contributions

KSA and SSS conceived the paper and wrote the manuscript. SHE and SWS contributed to the field trips, HJK and KHS to laboratory studies. All authors read and approved the final manuscript.

\section{Ethics approval}

This study was approved by the Animal Research Ethics Committee of Chonnam National University as complying with the Korean legislation for the animal protection (Low No. 13023, articles 8 and 9).

\section{Consent for publication}

Not applicable.

\section{Competing interests}

The authors declare that they have no competing interests.

\section{Publisher's Note}

Springer Nature remains neutral with regard to jurisdictional claims in published maps and institutional affiliations.

\section{Author details}

'Department of Parasitology, College of Veterinary Medicine, Chonnam National University, 77 Yongbong-ro, Buk-ku, Gwangju 61186, Republic of Korea. ${ }^{2}$ Department of Internal Medicine, College of Veterinary Medicine, Chonnam National University, 77 Yongbong-ro, Buk-ku, Gwangju 61186, Republic of Korea.

Received: 22 January 2018 Accepted: 5 March 2018

Published online: 20 March 2018

\section{References}

1. Gracia M, Calvete C, Estrada R, Castillo J, Peribanez M, Lucientes J. Fleas parasitizing domestic dogs in Spain. Vet Parasitol. 2008;151(2):312-9.

2. Harman DW, Halliwell RE, Greiner EC. Flea species from dogs and cats in north-central Florida. Vet Parasitol. 1987;23(1-2):135-40.

3. Koutinas AF, Papazahariadou MG, Rallis TS, Tzivara NH, Himonas CA. Flea species from dogs and cats in northern Greece: environmental and clinical implications. Vet Parasitol. 1995;58(1-2):109-15.

4. Wall R, Shaw S, Penaliggon J. The prevalence of flea species on cats and dogs in Ireland. Med Vet Entomol. 1997:11(4):404-6.

5. González A, del C Castro D, González S. Ectoparasitic species from Canis familiaris (Linné) in Buenos Aires Province, Argentina. Vet Parasitol. 2004; 120(1):123-9.

6. Cruz-Vazquez C, Gamez EC, Fernandez MP, Parra MR. Seasonal occurrence of Ctenocephalides felis felis and Ctenocephalides canis (Siphonaptera: Pulicidae) infesting dogs and cats in an urban area in Cuernavaca, Mexico. J Med Entomol. 2001:38(1):111-3.

7. Hopkins GHE, Rothschild M. An illustrated catalogue of the Rothschild Collection of fleas (Siphonaptera) in the British Museum (Natural History) with keys and short descriptions for the identification of families, genera, species and subspecies. Vol. I. Tungidae and Pulicidae. London: The Trustees of the British Museum; 1953. 
8. Wells K, Beaucournu J-C, Durden LA, Petney TN, Lakim MB, O'Hara RB, Ectoparasite infestation patterns of domestic dogs in suburban and rura areas in Borneo. Parasitol Res. 2012;111(2):909-19.

9. Lawrence A, Brown G, Peters B, Spielman D, Morin-Adeline V, Šlapeta J. High phylogenetic diversity of the cat flea (Ctenocephalides felis) at two mitochondrial DNA markers. Med Vet Entomol. 2014;28(3):330-6.

10. Changbunjong T, Buddhirongawatr R, Suwanpakdee S, Siengsanan J, Yongyuttawichai $\mathrm{P}$, Cheewajorn $\mathrm{K}$, et al. A survey of ectoparasitic arthropods on domestic animals in Tak Province, Thailand. Southeast Asian J Trop Med Public Health. 2009;40(3):435.

11. Beresford-Jones W. Prevalence of fleas on dogs and cats in an area of central London. J Small Anim Pract. 1981;22(1):27-9.

12. Kang $\mathrm{M}-\mathrm{H}$, Kim $\mathrm{H}-\mathrm{J}$, Jang $\mathrm{H}-\mathrm{J}$, Park H-M. Sensitization rates of causative allergens for dogs with atopic dermatitis: detection of canine allergenspecific IgE. J Vet Sci. 2014;15(4):545-50.

13. Clark DN. Culture and customs of Korea. Westport, Connecticut: Greenwood Publishing Group; 2000.

14. Yi JD. Globalization and recent changes to daily life in the Republic of Korea. In: Lewis J, Sesay A, editors. Korea and globalization: politics, economics and culture. New York: RoutledgeCurzon; 2002. p. 18-9.

15. Chee J-H, Kwon J-K, Cho H-S, Cho K-O, Lee Y-J, El-Aty AA, et al. A survey of ectoparasite infestations in stray dogs of Gwang-ju City, Republic of Korea. Korean J Parasitol. 2008;46(1):23.

16. Bitam I, Parola P, De La Cruz KD, Matsumoto K, Baziz B, Rolain J-M, et al. First molecular detection of Rickettsia felis in fleas from Algeria. Am J Trop Med Hyg. 2006;74(4):532-5.

17. Dryden MW, Rust MK. The cat flea: biology, ecology and control. Vet Parasitol. 1994;52:1-2):1-19.

18. Blanco JR, Pérez-Martínez L, Vallejo M, Santibáñez S, Portillo A, Oteo JA. Prevalence of Rickettsia felis-like and Bartonella spp. in Ctenocephalides felis and Ctenocephalides canis from La Rioja (northern Spain). Ann N Y Acad Sci. 2006;1078(1):270-4.

19. Krämer F, Mencke N. Flea biology and control: the biology of the cat flea control and prevention with imidacloprid in small animals. Berlin: SpringerVerlag $\mathrm{GmbH} ; 2001$.

20. Rolain J-M, Franc M, Davoust B, Raoult D. Molecular detection of Bartonella quintana, B. koehlerae, B. henselae, B. clarridgeiae, Rickettsia felis and Wolbachia pipientis in cat fleas, France. Emerg Infect Dis. 2003;9(3):339.

21. Bitam I, Dittmar K, Parola P, Whiting MF, Raoult D. Fleas and flea-borne diseases. Int J Infect Dis. 2010;14(8):e667-e76.

22. Azad AF, Beard CB. Rickettsial pathogens and their arthropod vectors. Emerg Infect Dis. 1998:4(2):179.

23. Downs WG. Polyvinyl alcohol: a medium for mounting and clearing biological specimens. Science. 1943;97(2528):539-40.

24. Hii S-F, Lawrence AL, Cuttell L, Tynas R, Rani PAMA, Šlapeta J, et al. Evidence for a specific host-endosymbiont relationship between 'Rickettsia sp. genotype RF2125' and Ctenocephalides felis orientis infesting dogs in India. Parasit Vectors. 2015;8(1):169.

25. Dunnet GM, Nardon D. A monograph of Australian fleas (Siphonaptera). Aust J Zool Suppl. 1974;22(30):1-273.

26. Gálvez R, Musella V, Descalzo MA, Montoya A, Checa R, Marino V, et al. Modelling the current distribution and predicted spread of the flea species Ctenocephalides felis infesting outdoor dogs in Spain. Parasit Vectors. 2017;10(1):428.

27. Alcaino HA, Gorman TR, Alcaino R. Flea species from dogs in three cities of Chile. Vet Parasitol. 2002;105(3):261-5.

28. Farkas R, Gyurkovszky M, Solymosi N, Beugnet F. Prevalence of flea infestation in dogs and cats in Hungary combined with a survey of owner awareness. Med Vet Entomol. 2009;23(3):187-94.

29. Beck W, Boch K, Mackesen H, Wiegand B, Pfister K. Qualitative and quantitative observations on the flea population dynamics of dogs and cats in several areas of Germany. Vet Parasitol. 2006:137:130-36.

30. Foley P, Foley J, Sándor A, lonică A, Matei I, D'Amico G, et al. Diversity of flea (Siphonaptera) parasites on red foxes (Vulpes vulpes) in Romania. J Med Entomol. 2017:54(5):1243-50.

31. Chesney C. Species of flea found on cats and dogs in south-west England: further evidence of their polyxenous state and implications for flea control. Vet Rec. 1995;136(14):356-8.

32. Marchiondo A, Holdsworth P, Fourie L, Rugg D, Hellmann K, Snyder D, et al. World Association for the Advancement of Veterinary Parasitology (WAAVP): guidelines for evaluating the efficacy of parasiticides for the treatment, prevention and control of flea and tick infestations on dogs and cats. Vet Parasitol. 2013;194(1):84-97.

33. Franc $M$, Choquart $P$, Cadiergues $M$. Répartition des espèces de puces rencontrées chez le chien en France. Rev Med Vet (Toulouse). 1998;149(2): $135-40$.

34. Lawrence AL, Hii S-F, Jirsová D, Panáková L, Ionică AM, Gilchrist K, et al. Integrated morphological and molecular identification of cat fleas (Ctenocephalides felis) and dog fleas (Ctenocephalides canis) vectoring Rickettsia felis in central Europe. Vet Parasitol. 2015;210(3):215-23.

35. Ashwini M, Puttalakshmamma G, Mamatha G, Chandranaik B, Thimmareddy P. Placid E, et al. Studies on morphology and molecular characterization of oriental cat flea infesting small ruminants by barcoding. J Ent Zool Stud. 2017:5(4):301-5.

\section{Submit your next manuscript to BioMed Central and we will help you at every step:}

- We accept pre-submission inquiries

- Our selector tool helps you to find the most relevant journal

- We provide round the clock customer support

- Convenient online submission

- Thorough peer review

- Inclusion in PubMed and all major indexing services

- Maximum visibility for your research

Submit your manuscript at www.biomedcentral.com/submit
) Biomed Central 